\title{
Investigating the Relationship among Test Anxiety, Gender, Academic Achievement and Years of Study: A Case of Iranian EFL University Students
}

\author{
Mohsen Rezazadeh (Corresponding author) \\ Department of English Language, \\ Faculty of Foreign Languages, University of Isfahan, Iran \\ E-mail: M1Rezazadeh@Gmail.com \\ Mansoor Tavakoli \\ Department of English Language, \\ Faculty of Foreign Languages, University of Isfahan, Iran \\ E-mail: Mr.tavakoli14@Gmail.com
}

\begin{abstract}
The construct of anxiety plays a major role in one's life. One of these anxieties is test anxiety or apprehension over academic evaluation. The present study was designed to investigate the relationship between gender, academic achievement, years of study and levels of test anxiety. This investigation is a descriptive analytic study and was done on 110 undergraduate students from University of Isfahan. The Suinn's Test Anxiety Questionnaire with 48 questions was used to gather the data. For analysis of data correlation coefficient and chi square test were used. The findings revealed that female students have a higher level of test anxiety in contrast to male students. The average of test anxiety score among female students was higher. Also a statistically significant negative correlation was observed between test anxiety and academic achievement. There was no meaningful relationship between test anxiety and years of study.
\end{abstract}

Keywords: Test anxiety, Gender, Academic achievement, Years of study, Iranian EFL University students

\section{Introduction}

Too much anxiety about a test is commonly referred to as test anxiety. It is perfectly natural to feel some anxiety when preparing for and taking a test. Test anxiety is really common among college students! It is normal to feel some level of anxiety or stress regarding upcoming exams, papers or presentations. Examination stress and test anxiety are pervasive problems in modern society. As the information age continues to evolve, test scores will become even more important than they are today in evaluating applicants for demanding jobs and candidates for admission into highly competitive educational programs. Because test anxiety generally causes decrements in performance and undermines academic achievement, the development of effective therapeutic interventions for reducing its adverse effects will continue to be an important priority for counselors, psychologists, and educators. Alleviating test anxiety will also serve to counteract the diminished access to educational and occupational opportunities that is frequently experienced by test-anxious individuals.

Every year, millions of students under-perform in school and university because of heightened test anxiety, which is defined as the "set of phenomenological, physiological, and behavioral responses that accompany concern about possible negative consequences or failure on an exam or similar evaluative situation" (Zeidner, 1998, p.17). Although test anxiety is known to depend on situational variables, such as levels of motivation, task complexity, and the practical consequences of high or low performance (Humphreys \& Revelle, 1984), it varies markedly from one individual to another. Thus, some individuals will be relatively calm when it comes to completing a test, whilst others will generally "perceive examinations as more dangerous or threatening and experience more intense levels of state anxiety when taking tests" (Spielberger \& Vagg, 1995, p.6). On the self-defeating consequences of subjective cognitions (Ellsworth \& Smith, 1988; Lazarus, 1991) suggest that poorer self-beliefs are a major cause of test anxiety.

Test anxiety has emerged as one of the most salient constructs in modern-day psychology and by far the most widely studied specific form of anxiety in the literature. Test anxiety is a ubiquitous phenomenon, with some degree of evaluative anxiety being experienced by most people in modern society. The test anxiety construct has matured within a large cocoon of attention ever since its inception in the early 1950s, with researchers making important strides toward understanding its nature, components, origins, determinants, effects, and treatments. The importance of test anxiety in understanding sources of student stress in evaluative situations and poor test performance is now readily apparent. The topic of test anxiety has prospered, in part, due to the increasing personal importance of test situations for people in modern society, making tests and their long-term consequences significant educational, social, and clinical problems for many. Since test results in most academic and occupational settings have important practical implications for a person's 
goals and future career, test anxiety is frequently reported to be a meaningful factor impacting upon test scores. In fact, much of the test anxiety research over the past half century has been motivated by the desire to ameliorate the debilitating levels of test anxiety in various settings and populations and to find ways of helping test-anxious persons become more effective in test or test like situations. Over the past few decades there has been an upsurge of interest in test anxiety research among psychological and educational researchers. Literally hundreds of researchers have investigated the nature, antecedents, correlates, and consequences of test anxiety, and the literature is prodigious. A wealth of studies relating to various facets of test anxiety has appeared in some of the premiere journals in psychology and education. Test anxiety has become a major topic of research interest in education and various subareas of psychology, including personality and social psychology, educational and developmental psychology, cognitive psychology, health psychology, counseling and clinical psychology.

\section{Background}

Research on test anxiety has a long and fruitful history. First studies relating to test anxiety were conducted as early as 1914 (Folin, Demis \& Smillie, 1914), and the concept began to be investigated under its own name in 1952, when Mandler and Sarason (Sarason \& Mandler, 1952) published a series of studies on test anxiety and how it relates to performance, as well as developed an instrument to assess individual differences in test anxiety in adults, the Test Anxiety Questionnaire.

The increasing interest in outcome-based approaches to assessment and reporting in language testing (e.g., Brindley, 1998; McKay, 2000) has heightened the need for more research on fair assessment (Kunnan, 2000) by which more valid inferences can be drawn. Although assessment can be done without tests (e.g., portfolios, and self- and peer-assessments, Brown and Hudson, 1998), of particular interest and complexity is assessment based on tests. The current research focuses on one variable related to test-takers' characteristics, namely test anxiety, and investigates to what extent test anxiety affects listening test performance.

According to Bachman and Palmer (1996), test performance is attributed to test-taker and test task characteristics. The test-taker qualities consist of (a) topical knowledge, (b) language knowledge, (c) personal trait, (d) strategic competence, and (e) affective schemata. Of these attributes, the former three interact with the latter two. The test-taker and test task traits have effects on each other, and as a consequence, test performance results from these interactions. Since our decisions or inferences based on test performance depend on these characteristics, it is very important to know how these components affect test performance. Although these variables all merit investigation, a central issue seems to be how personal traits influence test performance. There are many types of personal attributes related to test performance (e.g., age, sex, nationality, Bachman and Palmer, 1996, p. 65), but one which is of great significance is test anxiety. Test anxiety refers to a "special case of general anxiety consisting of phenomenological, physiological, and behavioral responses" related to a fear of failure (Sieber, 1980, p. 17) and to the "experience of evaluation or testing" (Sieber, 1980, p. 18). Test anxiety may occur due to test-takers' lack of learning or study skills (Culler and Holahan, 1980; Wittmaier, 1972). Generally, test anxiety is negatively correlated with test performance in the field of psychology (e.g., Sapp, 1999; Zeidner, 1998). Although many studies have been conducted, one conclusive research work is a meta-analysis study (Hembree, 1988) that uses correlation coefficients between a wide range of measures of performance and test anxiety based on 562 North American studies published from 1952 through 1986. Results show that test anxiety scores are negatively and very weakly related to grades in reading and English $(r=-0.24)$ and foreign language $(\mathrm{r}=-0.12)$.

In contrast, in the context of second language studies, anxiety in a more general sense is considered in attitudes and motivation studies (Gardner, 1985; MacIntyre and Gardner,1991), and especially foreign language anxiety (e.g., Bailey et al., 1999; Elkhafaifi, 2005; Horwitz, 2001; Phillips, 1992) has often been examined. Previous researches have shown that males typically score lower on measurements of test anxiety than females (Lashkaripour, 2006; Berger \& Schecter, 1996; Mehregan \& Najjarian \& Ahmadi 2001; Ferrando et al, 1999; Chang, 1997; Feingold, 1994). The different test anxiety constructs affect males and females in different ways. Results show that: (a) worry was related to task-orientation and preparation and low avoidance coping in females; (b) emotionality was related to seeking social support in male students and to task-orientation and preparation in female students; and (c) interference was related to avoidance coping in females (Stober, 2004). There was a gender effect on worry and emotionality test anxiety for high achieving students. Overall, females were reported to be more subject to test anxiety than males; and females experienced higher worry than emotionality, while males reported little difference between the two dimensions (Everson, Millsap, \& Rodriquez, 1991).

\section{Research questions and hypotheses}

The present study was conducted to investigate the relationship between test anxiety and other variables such as: gender, academic achievement, and years of study. In order to define its goals three research questions were set:

Q1: Is there a higher test anxiety among female students than male students? 
Q2: Is there any relationship between test anxiety and academic achievement among university students?

Q3: Is there any relationship between test anxiety and years of study among university students?

To answer the above questions the following null hypothesis were tested.

HO 1: There is no difference between males and females considering the rate of test anxiety.

HO 2: There is no relationship between test anxiety and academic achievement.

H0 3: There is no relationship between test anxiety and years of study.

By dint of SPSS software several statistical procedures were utilized. The results are presented in the following sections.

\section{Method}

\subsection{Participants}

Participants were 110 undergraduate students from University of Isfahan. There were 65 females and 45 males. It is usually a general feature of the population at this university that females outnumber males. Students were English undergraduates who volunteered to take part in this study. Stratification of the sample was done by obtaining a random proportional sample of classes within English Department to ensure that a wide variety of students of different ability levels were involved. In terms of college status, 25 were freshmen, 35 were sophomores, 19 were juniors, and 31 were senior students.

\subsection{Instrument}

The Test Anxiety Questionnaire (Suinn, 1969, Revised by Summer 2002) was used to assess test anxiety in this study. It can be described as a 48-item, 5-point, Likert-type instrument. Students were required to read the assertions, and then check the scale number which indicated how much they are frightened when in the mentioned situation. For example, for the item: "How much are you frightened by hearing the announcement of a coming test?", the student would then respond by checking either: 1=Not At All; 2=A Little; 3=A Fair Amount; 4=Much; 5=Very Much. A Test Anxiety Index (TAIN) score can be calculated by summing the scores for each item. A score of 160 or higher indicates that the student may have a problem with test anxiety. Data were collected from students during their schedule class time. For analysis of data correlation coefficient, chi square test and mean were used.

\section{Results and discussion}

\subsection{Test anxiety status}

Test Anxiety score can be calculated by summing the scores for each item of the questionnaire. A score of 160 or higher indicates that the student may have a problem with test anxiety. Scores between "80-160" indicates that the students in this group have a moderate level of test anxiety. The score that is lower than 80 indicates that the student has a low test anxiety level. Among the population in this study $(\mathrm{n}=110) 13(11.8 \%)$ have high test anxiety level, $81(73.6 \%)$ have a moderate level of test anxiety, and $16(14.5 \%)$ have low test anxiety level.(see table 1).

\subsection{Analysis 1}

In the first analysis the researcher's purpose was to test the first null hypothesis "There is no difference between males and females considering the rate of test anxiety". Comparing the mean of test anxiety scores between male and female students shows that there is a meaningful difference between males and females considering the rate of test anxiety. As it is shown in table 2 the mean of test anxiety score for female students $(X=123.72, S D=35)$ was higher than the mean of test anxiety score for male students ( $\mathrm{X}=113.27, \mathrm{SD}=32.14)$.

The researcher compared the two groups by their answers, too. Comparing male and female students considering the frequency and percentage of their answers to each question on the figure shows a meaningful difference (see table $3 \&$ figure 1).

\subsection{Analysis 2}

In the second analysis, the researcher aimed at finding the relationship between test anxiety and academic achievement. To test the second null hypothesis "There is no relationship between test anxiety and academic achievement" the data collected by test anxiety questionnaire (test anxiety scores) and the students' GPA (grade point average) were correlated with each other. For so doing, a Pearson correlational procedure was conducted. The level of acceptance was set at 0.03 . The results are presented in table 4 . As the table shows, there is a negative correlation between these two variables at the level 0.199 . The procedure yielded a correlation coefficient of -0.199 . A reverse ratio was observed between test anxiety and academic achievement.

The students are divided into three groups considering their GPA. The first group (or group A) consisted of students whose GPAs' are ranged from 20 to 17. The second group (or group B) consisted of students whose GPAs' ranged from 
17 to 15 . The third group (or group C) consisted of students whose GPAs' are ranged from 15 to 12 . As it can be seen in table 5, group A has the lowest level of test anxiety $(\mathrm{X}=113.24)$ and group $\mathrm{C}$ has the highest level of test anxiety $(\mathrm{X}=130.33)$. It means that as test anxiety level increases, educational achievement decreases and vice-versa.

\subsection{Analysis 3}

In the third analysis the researcher intends to test the third null hypothesis "There is no relationship between test anxiety and years of study". In table 6 chi-square tests were conducted. The results show that there is no meaningful relationship between test anxiety and years of study.

Comparing the mean of test anxiety scores between four groups of students considering their years of study shows that juniors have the highest test anxiety level. In terms of college status, 25 were freshmen, 35 were sophomores, 19 were juniors, and 31 were senior students. As it is shown in table 7 seniors have the lowest level of test anxiety $(X=114.35)$ and juniors have the highest $(\mathrm{X}=132)$.

\section{Conclusion}

The primary purpose of this study was to investigate the relationship between test anxiety and gender. Findings show that $11.8 \%$ of students in our sample suffer from test anxiety. The mean of test anxiety score among female students was meaningfully higher than the mean of test anxiety score among male students. Also, results reveal that there is a reverse ratio between test anxiety and educational achievement and this relationship was meaningful. The last analysis shows that there is no meaningful relationship between test anxiety and years of study.

Females reported significantly higher levels of test anxiety than males. This is consistent with the previous researches on gender effects on test anxiety (Mousavi \& Haghshenas \& Alishahi, 2008; Lashkaripour, 2006; Mehregan \& Najjarian \& Ahmadi, 2001; Ferrando et al, 1999; Bishop \& Baner \& Becker 1998; Chang, 1997; Berger \& Schecter, 1996; Feingold, 1994). However, this difference has not been evidenced by some researches (Mwamwenda, 1993). The difference in the socialization patterns of males and females has been the primary explanation for this difference. More pressure is placed on females to succeed in school than males. This leads to the increase in test anxiety levels because girls essentially are afraid to fail; each testing situation is seen as another possible chance of failure. Another possible explanation is that "males are more defensive about admitting anxiety because it might be seen as threatening to their masculinity; they are trained to cope with anxiety by denying it or by finding ways to overcome it" (Mousavi \& Haghshenas \& Alishahi, 2008).

In the second analysis the results showed that there is a negative relationship between test anxiety and educational achievement. Some past studies have more or less obtained the same findings. The results with regard to educational achievement are also in line with those obtained from other studies by Lashkaripour (2006), Moore (2006), Mwamwenda (1994), Comunian (1993). All have reached the conclusion that educational achievement and test anxiety level have a reverse ratio. It means that as test anxiety level increases, educational achievement decreases and vice-versa.

The third analysis, not so unexpectedly, reveals that there is no meaningful relationship between test anxiety and years of study. Finding no relationship between these two variables was not surprising, since past studies did not pay much attention to this part. Psychological phenomena are among the most sophisticated concepts. Therefore, discovering the relations and connections within this intertwined web is not an easy task. It requires lots of research and long studies to explain them.

\section{Acknowledgments}

We thank all the participants, and appreciate the views and comments of the reviewers.

\section{References}

Bachman, L.F., \& Palmer, A. (1996). Language Testing in Practice. Oxford University Press, Oxford.

Bailey, P., Daley, C.E., \& Onwuegbuzie, A.J. (1999). Foreign language anxiety and learning style. Foreign Language Annals 32, 63-76.

Berger, R., \& Shechter, Y. (1996). Guidelines for choosing an "intervention package" for working with adolescent girls in distress. Adolescence, 31, 709-717.

Bishop, J.B., Baner, K.W \& Becker, E.T. (1998). A survey of counseling needs of male and female college students. Journal of College Student Development, 39 (2), 205-210.

Brindley, G. (1998). Outcome-based assessment and reporting in language learning programmes: a review of the issues. Language Testing 15, 45-85.

Brown, J.D., \& Hudson, T. (1998). The alternatives in language assessment. TESOL Quarterly 32, 653-675.

Chang, J. I. (1997). Contexts of adolescent worries: Impacts of ethnicity, gender, family structure, and socioeconomic 
status. Paper presented at the annual meeting of NCFR Fatherhood and Motherhood in a Diverse and Changing World, Arlington, VA.

Comunian A.L. (1993). Anxiety, cognitive interference, and school performance of Italian children. Psychological Reports, 73, 747-54.

Culler, R.E., \& Holahan, C.J. (1980). Test anxiety and academic performance: the effects of study-related behaviors. Journal of Educational Psychology, 72, 16-20.

Elkhafaifi, H. (2005). Listening comprehension and anxiety in the Arabic language classroom. The Modern Language Journal 89, 206-220.

Ellsworth, P. C., \& Smith, C. A. (1988). From appraisal to emotion: Differences 401 among unpleasant feelings. Motivation and Emotion, 12, 271-302.

Everson, H. T., Millsap, R. E., \& Rodriquez, C. M. (1991). Isolating gender differences in test anxiety: A confirmatory factor analysis. Educational and Psychological Measurement, 51, 243-251.

Ferrando, P. et al. (1999). A Psychometric Study of the Test Anxiety Scale for Children in a Spanish Sample. Personality and Individual Differences, 27(1), 37-44.

Feingold, A. (1994). Gender Differences in Personality: A Meta analysis. Psychological Bulletin, 16, 429-456.

Folin, O., Denis, W. \& Smillie, W.G. (1914). Some observationson "emotional glycosuria” in man. Journal of Biological Chemistry, 17, 519-520.

Gardner, R.C. (1985). Social Psychology and Second Language Learning: The Role of Attitudes and Motivation. Arnold, London.

Hembree, R. (1988). Correlates, causes, effects, and treatment of test anxiety. Review of Educational Research 58, 47-77.

Horwitz, E.K. (2001). Language anxiety and achievement. Annual Review of Applied Linguistics 21, $112-126$.

Humphreys, M. S., \& Revelle, W. (1984). Personality, motivation, and performance: A theory of the relationship between individual differences and information processing. Psychological Review, 91, 153-184.

Kunnan, A.J. (2000). Fairness and justice for all. In: Kunnan, A.J. (Ed.), Fairness and Validation in Language Assessment: Selected Papers from the Nineteenth Language Testing Research Colloquium, Orland, Florida. Cambridge University Press, Cambridge, 1-14.

Lashkaripour, K (2006). The relationship between test anxiety and academic achievement in students of guidance schools in Zahedan. Tabib Shargh Journal, $8^{\text {th }}$ year, No 4, winter 85.

Lazarus, R. S. (1991).Emotion and adaptation. New York: oxford University Press.

MacIntyre, P.D., \& Gardner, R.C. (1991). Language anxiety: Its relationship to other anxieties and to processing in native and second languages. Language Learning 41, 513-534.

McKay, P. (2000). On ESL standards for school-age learners. Language Testing 17, 185-214.

Mehregan F., Najjarian B. \& Ahmadi A. (2001). The relation between test anxiety and performance among Ahvaz university students. Ferdowsi J Psychol, 2, 7-24.

Mousavi, M., Haghshenas, H., \& Alishahi, M.J. (2008). Effect of gender, school performance and school type on test anxiety among Iranian adolescents. Iranian Red Crescent Medical Journal, 10, January, 4-7.

Mwamwenda, T.S. (1994). Test Anxiety and academic achievement among South African University students. Psychological Reports, 75, 1593-1594.

Mwamwenda T.S. (1993). Gender differences in test anxiety among South African University students. Perceptual Motor Skills, 76, 554-564.

Phillips, E.M. (1992). The effects of language anxiety on students' oral test performance and attitudes. The Modern Language Journal 76, 14-26.

Sapp, M. (1999). Test Anxiety: Applied Research, Assessment, and Treatment Interventions, 2nd ed. University Press of America, Lanham, MD.

Sarason, S.B. \& Mandler, G. (1952). Some correlates of test anxiety. Journal of Consulting and Clinical Psychology, 47, 810-817.

Sieber, J.E. (1980). Defining test anxiety: problems and approaches. In: Sarason, I.G. (Ed.), Test Anxiety: Theory, Research and Applications. Lawrence Erlbaum Asssociates, Hillsdale, NJ, pp. 15-42. 
Spielberger, C. D., \& Vagg, P. R. (1995). Test anxiety: A transactional process. In C. D. Spielberger \& P. Vagg (Eds.), Test anxiety: theory, assessment, and treatment (pp. 3-14). Washington, DC: Taylor \& Francis.

Stober, J. (2004). Dimensions of test anxiety relations to ways of coping with pre-exam anxiety and uncertainty. Anxiety, Stress, and Coping, 17, 213-226.

Wittmaier, B.C. (1972). Test anxiety and study habits. Journal of Educational Research 65, 352-354.

Zeidner, M. (1998). Test anxiety: The state of the art. New York: Plenum.

Table 1. Test Anxiety Status

\begin{tabular}{lcccccc}
\hline TA status & \multicolumn{2}{c}{ Total } & \multicolumn{2}{c}{ Male students } & \multicolumn{2}{c}{ Female students } \\
& Percent & Frequency & Percent & Frequency & Percent & Frequency \\
\hline High & 11.8 & 13 & 3.6 & 4 & 8.1 & 9 \\
\hline Moderate & 73.6 & 81 & 29.7 & 9 & 44.5 & 49 \\
\hline Low & 14.5 & 16 & 8.1 & 32 & 6.3 & 7 \\
\hline
\end{tabular}

Table 2. Test Anxiety Score and Gender

\begin{tabular}{cccccc}
\hline Gender & Mean & Std. Deviation & Variance & Std. Error of Mean & Range \\
\hline Female & 123.72 & 35.001 & 1.225 & 4.341 & 155 \\
\hline Male & 113.27 & 32.148 & 1.033 & 4.792 & 123 \\
\hline Total & 119.45 & 34.105 & 1.163 & 3.252 & 169 \\
\hline
\end{tabular}

Table 3. Frequency and percentage of the student's answers

\begin{tabular}{lcccc}
\hline & \multicolumn{2}{c}{ Male students } & \multicolumn{2}{c}{ Female students } \\
Answers & frequency & percent & frequency & percent \\
\hline 1.Not at all & 661 & 30.6 & 712 & 22.8 \\
\hline 2.A little & 645 & 29.9 & 928 & 29.8 \\
\hline 3.A fair amount & 423 & 19.6 & 719 & 23.1 \\
\hline 4.Much & 278 & 12.9 & 483 & 15.5 \\
\hline 5.Very much & 153 & 7.1 & 277 & 8.9 \\
\hline
\end{tabular}

Table 4. TA score \& GPA Correlations

\begin{tabular}{llcc}
\hline & & GPA & TA Score \\
\hline \multirow{2}{*}{ GPA } & Pearson Correlation & 1 & -.199 \\
\cline { 2 - 4 } & Sig. (2-tailed) & & .037 \\
\cline { 2 - 4 } & $\mathrm{N}$ & 110 & 110 \\
\hline \multirow{2}{*}{$\begin{array}{l}\text { Test Anxiety } \\
\text { Score }\end{array}$} & Pearson Correlation & -.199 & 1 \\
\cline { 2 - 4 } & Sig. (2-tailed) & .037 & \\
\cline { 2 - 4 } & $\mathrm{N}$ & 110 & 110 \\
\hline
\end{tabular}

Table 5. Test Anxiety Scores and Educational Achievement

\begin{tabular}{cccccc}
\hline GPA & Mean & Std. Deviation & Variance & Std. Error of Mean & Range \\
\hline A (20-17) & 113.24 & 34.931 & 1.220 & 7.623 & 116 \\
\hline B (17-15) & 118.52 & 34.364 & 1.181 & 4.078 & 169 \\
\hline C (15-12) & 130.33 & 31.358 & 983.294 & 7.391 & 120 \\
\hline Total & 119.45 & 34.105 & 1.163 & 3.252 & 169 \\
\hline
\end{tabular}

Table 6. Chi-Square Tests

\begin{tabular}{lccc}
\hline & Value & df & $\begin{array}{c}\text { Asymp. Sig } \\
\text { (2-sided) }\end{array}$ \\
\hline Pearson Chi-Square & 5.622 & 6 & .467 \\
Likelihood Ratio & 5.739 & 6 & .453 \\
N of Valid Cases & 110 & & \\
\hline
\end{tabular}


Table 7. Test Anxiety Scores and Years of study

\begin{tabular}{lccccc}
\hline Years of study & Mean & Std. Deviation & Variance & Std. Error of Mean & Range \\
\hline Seniors & 114.35 & 30.113 & 906.770 & 5.408 & 110 \\
\hline Juniors & 132.00 & 21.584 & 465.889 & 4.952 & 94 \\
\hline Sophomores & 118.23 & 42.007 & 1.765 & 7.100 & 169 \\
\hline Freshmen & 117.92 & 33.721 & 1.137 & 6.744 & 136 \\
\hline Total & 119.45 & 34.105 & 1.163 & 3.252 & 169 \\
\hline
\end{tabular}

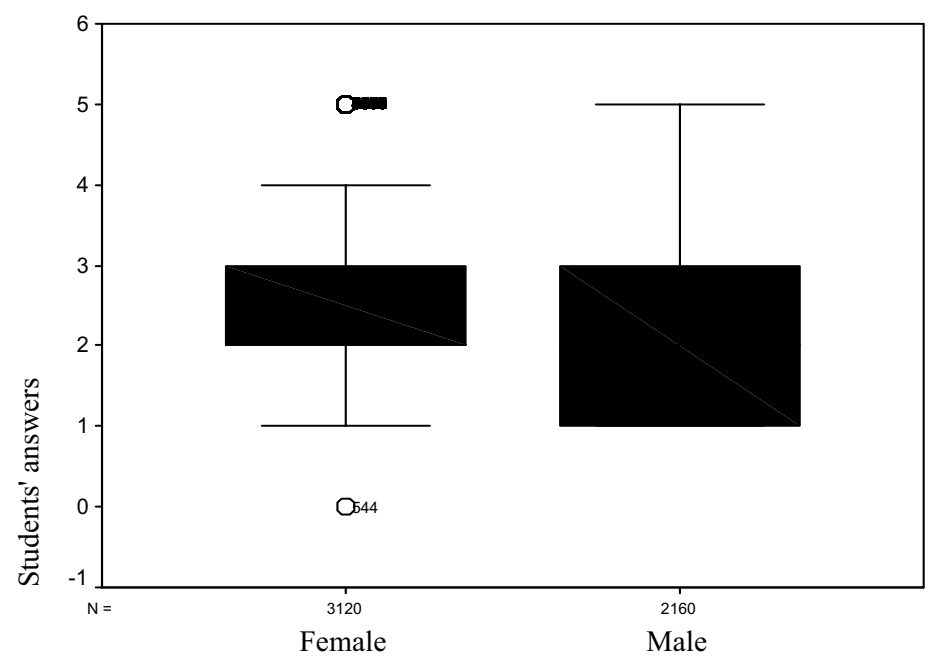

Figure 1. Comparing male and female students considering the frequency of their answers to each question. 